\title{
Panorama do uso de ambientes virtuais na Educação Profissional e Tecnológica
}

\author{
Adriana Zanki Cordenonsi - IFRO/RO - PPGEPT/CTISM-UFSM - \\ adriana.cordenonsi@ifro.edu.br https://orcid.org/0000-0002-7904-4932 \\ Fernando Menegatti - IFRS/RS - PPGEPT/CTISM-UFSM - menegatti.fernando@gmail.com \\ https://orcid.org/0000-0002-0301-4040 \\ Gabriela Machado Saldanha - PPGEPT/CTISM-UFSM - gabisaldanhadireito@gmail.com \\ https://orcid.org/0000-0001-7399-6062 \\ Jairo Manzoni Rodrigues - FISMA/RS -PPGEPT/CTISM-UFSM - jairomanzoni@gmail.com \\ https://orcid.org/0000-0002-1282-3421 \\ Tainan Silva Garcia - FISMA/RS - PPGEPT/CTISMUFSM - tainan_garcia@hotmail.com \\ https://orcid.org/0000-0002-5345-9013 \\ Claudia Smaniotto Barin - CCNE - PPGEPT/CTISM/UFSM -claudiabarin@ufsm.br \\ https://orcid.org/0000-0002-6549-5476
}

Resumo: Com a necessidade de mediação pedagógica online, os ambientes virtuais surgem como alternativa para mediação e acompanhamento da aprendizagem. Neste contexto, este trabalho visa compreender como os ambientes virtuais têm sido utilizados na Educação Profissional e Tecnológica, no período pandêmico. A abordagem é do tipo descritiva, sendo sujeitos da pesquisa 239 professores da Educação Profissional. A coleta de dados se deu por meio de um questionário com perguntas abertas e fechadas. Conforme os dados coletados, o ambiente virtual mais utilizado é o Moodle, seguido do Classroom e a escolha se dá de forma institucional. A maior dificuldade apontada pelos professores é a gestão do tempo de trabalho e a criação de materiais e atividades mais atrativas. Dentre as vantagens os professores citam a adequação e organização de conteúdos.

Palavras-chave: EPT. Ambientes Virtuais de ensino e aprendizagem. Mediação pedagógica.

\section{Overview of the use of virtual environments in Professional and Technological Education in the Covid-19 Pandemic}

\begin{abstract}
In view of the need for online pedagogical mediation, virtual environments emerge as an alternative for mediation and monitoring learning. In this context, this work aims to understand how virtual environments have been used in Vocational and Technological Education during the pandemic period. The approach is descriptive, with 239 Professional Education teachers being research subjects. Data collection took place through a questionnaire with open and closed questions. According to the collected data, the most used virtual environment is Moodle, followed by Classroom and the choice is made institutionally. The biggest difficulty pointed out by the teachers is the management of working time and the creation of more attractive materials and activities. Among the advantages, teachers mention the adequacy and organization of content.
\end{abstract}

Keywords: VTE. Virtual teaching and learning environment. Pedagogical mediation.

\section{Introdução}

Em 2020, com a necessidade de distanciamento social decorrente da pandemia do COVID-19, viu-se uma necessidade iminente de encontrar alternativas para a mediação V. $19 \mathrm{~N}^{\mathrm{o}} 1$, julho, 2021

DOI: https://doi.org/10.22456/1679-1916.118386 RENOTE 
pedagógica e a manutenção do vínculo com os estudantes em todas as modalidades de ensino (MOREIRA et al., 2020; SANTOS JR.; MONTEIRO, 2020). Dentre estas modalidades de ensino, os cursos voltados à formação para o exercício da profissão, ou seja, os cursos de Educação Profissional e Tecnológica (EPT), requerem um olhar atento, visto que, em sua maioria, possuem um viés prático, requerendo metodologias de ensino diferenciadas, que promovam o desenvolvimento de habilidades e competências, além do saber teórico.

Neste contexto de distanciamento social, a mediação pedagógica precisou se reinventar. Assim, embora há décadas os AVEA - Ambientes Virtuais de Ensino e Aprendizagem - fossem disponíveis em instituições de ensino, estes ganharam destaque no último ano, como alternativa viável para disponibilização de conteúdos, partilhas, construção de saberes e processos avaliativos. Como apontam Costa et al. (2012):

\begin{abstract}
Os ambientes virtuais de aprendizagem concentram diferentes recursos e ferramentas de comunicação síncrona e assíncrona, que representam um arsenal tecnológico com elevado potencial. No entanto, todo esse aparato tecnológico, por mais encantador que possa parecer em um primeiro momento, não garante por si só condições para os processos de interação, cooperação e aprendizagem, uma vez que depende diretamente da metodologia aplicada (COSTA et al, 2012, p.2).
\end{abstract}

Barin, Bastos e Marshall (2013), apontam que as pesquisas acerca das potencialidades dos ambientes AVEA no processo de mediação pedagógica, tanto no ensino a distância, como no híbrido e presencial, vêm se ampliando. Isto se deve, em parte, à adoção destes ambientes nas instituições de ensino, quer como meio de ampliação da sala de aula ou como ferramenta de distribuição de conteúdos, numa perspectiva de confluência das modalidades presencial e a distância. Essa visão é corroborada por De Brito et al. (2013), que afirmam que o uso dos AVEA se dá grande parte das vezes num viés mais instrucionista que interativista.

Nesse sentido, investigar como os AVEA, são utilizados na EPT, vai além de simplesmente mapear qual ambiente é mais utilizado, mas investigar como se dá seu uso e os maiores desafios encontrados. Dentro desta perspectiva, o presente trabalho visa traçar um panorama do uso dos ambientes virtuais de ensino e aprendizagem na EPT.

\title{
Ambientes Virtuais de Ensino e Aprendizagem
}

Os AVEA são plataformas digitais que permitem a criação e distribuição de conteúdos, bem como o acompanhamento dos estudantes. Atualmente, existe uma vasta gama de ambientes virtuais, sendo os mais conhecidos o Moodle, o Google Classroom, o Edmodo e o Teams. Fazendo uma breve pesquisa por ambientes virtuais na revista Renote, o Modular Object Oriented Dynamic Learning Environment - Moodle, é o ambiente mais citado. Esse fato pode estar associado ao fato do mesmo ser uma das plataformas mais utilizadas tanto nacional como internacionalmente, como afirmam Gomes e Pimentel (2021).

Ruy e Belda (2021) apresentam um estudo comparativo entre os ambientes virtuais Moodle e Google Classroom. Para isto os autores criaram um curso em ambos ambientes e avaliaram as potencialidades e desafios de cada um. Segundo eles,

\footnotetext{
ambas as plataformas atendem aos objetivos do curso desenvolvido, mas que o Moodle é o mais adequado quando consideramos que se pretende atingir uma imensa demanda de cursistas, esbarrando, entretanto, na necessidade de um servidor que o hospede gratuitamente e sem limites de estudantes matriculados (RUY; BELDA, 2021, p.1)
} 
Se por um lado o Moodle requer um servidor para hospedagem, o mesmo propicia a customização, visto que é um software livre, que possibilita diferentes configurações atendendo às necessidades de cada usuário ou instituição de ensino.

Em contrapartida, o Google Classroom tem tido excelente aceitação pelos discentes, principalmente pela facilidade de uso, como afirmam Al-Maroof e Al-Emran (2018), ou ainda pela integração com outros apps da Google. As vantagens do Google Classroom são corroboradas por Da Silva $(2020$, p.1) "é uma ferramenta didática que poderá potencializar o Ensino Híbrido na Educação Básica porque é fácil de ser utilizada, acessível e possibilita que o aluno estude em qualquer lugar com acesso à internet".

\section{Metodologia}

A pesquisa trata-se de um estudo de campo, de caráter descritivo, visto que discorre sobre as características de uma população específica, professores da Educação Profissional e Tecnológica, e estabelece relações destes com os AVEA.

O público consistiu de 239 professores, atuantes nos cursos de EPT de diferentes instituições brasileiras. $\mathrm{O}$ instrumento de coleta de dados foi um questionário do tipo survey, produzido com a ferramenta Google formulários, contendo perguntas abertas e fechadas que visavam caracterizar o público respondente (idade, sexo, experiência profissional, local de atuação, estado onde reside), bem como investigar sobre o uso dos AVEA (quais ferramentas utiliza para mediação pedagógica, a escolha do ambiente, tipo de recursos e atividades que disponibiliza, vantagens do uso, participação dos discentes no ambiente e dificuldades encontradas), conforme pode ser visualizado no sítio: <https://docs.google.com/forms/d/e/1FAIpQLSechtN-tKzLt-MUAEz5hkiF4GTZCZhTjqZQaDbb7JKz-yT-Q/viewform>.

$\mathrm{O}$ instrumento de coleta foi aplicado entre março e abril/2021. Os dados coletados foram analisados quantitativamente, por meio de percentuais, médias e/ou desvios, bem como qualitativamente por meio de categorias de análise elencadas a posteriori, de acordo com Bardin (2011), definidas após leitura flutuante, agrupamentos e codificação de dados.

\section{Resultados e Discussão}

\section{Caracterização do Público alvo}

A amostra consistiu de 239 professores atuantes na Educação Profissional e Tecnológica, sendo a maioria destes dos estados do RS (56,1\%) e RO (33.9\%). Os demais participantes atuam nos estados do PR $(0,42 \%)$, SC $(1,3 \%)$, CE $(0,42 \%)$, BA $(0,84 \%)$, SE $(0,42 \%)$, GO $(0,42 \%)$, TO $(3,4 \%)$, MG $(0,84 \%)$, RJ $(0,84 \%)$, ES $(0,42 \%)$ e SP $(0,42 \%)$. Comparando os dois maiores percentuais com os dados da Plataforma Nilo Peçanha ${ }^{1}$, os respondentes de RO representam 11,5\% dos professores do Estado, enquanto que os respondentes do RS, representam 3,80\% dos professores do Estado.

A maior parte dos participantes $(93,7 \%)$ é professor em Institutos Federais, 2,5\% de Escolas Técnicas associadas à Instituições de Ensino Superior Federais, 2,1\% à instituições de EPT privadas, 0,4\% do sistema $\mathrm{S}$ de Ensino Profissional, 0,4\% das Instituições Estaduais de EPT e 0,8\% dos Centros Federais de Educação Tecnológica. O grande número de respondentes do Institutos Federais (IF) está em consonância com os dados da Plataforma Nilo Peçanha ${ }^{1}$, que aponta que a maioria das escolas de formação profissional na esfera federal é constituída pelos IF (93\%). 
A média de idades dos participantes da pesquisa é de $42,3 \pm 9,3$, sendo a maioria constituída de mulheres $(56,1 \%)$. Estes dados são relevantes, em primeiro lugar, devido ao fato da idade poder estar correlacionada ao uso ou não uso das tecnologias da informação e da comunicação (TIC) e segundo, visto que grande parte do público feminino exerce dupla jornada de trabalho, uma no âmbito da profissão e outra nas atividades do cotidiano da família, como afirmam Zibetti e Pereira (2010), e podem ter assim, implicações nas respostas posteriores.

Os professores atuam em diversas áreas de ensino, sendo as áreas de Matemática e suas Tecnologias e de Informática, as que apresentam maior frequência (54 professores), seguida das áreas de Linguagem e suas Tecnologias (38 professores), Biologia, Química e Administração (24 professores), Eletroeletrônica, Física e Ciências Agrárias, (14 professores), Engenharias (12 professores). Os demais professores distribuem-se em outras áreas como Alimentos, Moda, Geografia, História, Filosofia.

Com base nos dados retornantes, inferimos que apenas $27,6 \%$ possui até 5 anos de experiência. Apenas 20,5\% tem experiência de 6 a 10 anos, 29, 7\% tem experiência entre 11 e 15 anos e por fim, 21,8\% possui experiência superior a 15 anos na docência. Estes dados nos permitem inferir que a maioria dos respondentes já possui experiência na docência, o que lhes confere um saber diferente, denominado por Tardif (2007), de saber experiencial. De acordo com Tardif (2007), os saberes experienciais vão além dos disciplinares e curriculares, adquiridos na formação inicial ou continuada e, são adquiridos ao longo da trajetória docente. Este saber, imbricado com a fluência tecnológica pode influir na performance docente.

\section{Uso dos ambientes virtuais}

O primeiro questionamento feito aos professores foi sobre quais ferramentas os mesmos utilizaram para mediação pedagógica, durante a pandemia do Covid-19. Como era de se esperar, os ambientes virtuais, assim como as redes sociais e as ferramentas de webinar, foram as mais citadas, como pode-se observar na Figura 1.

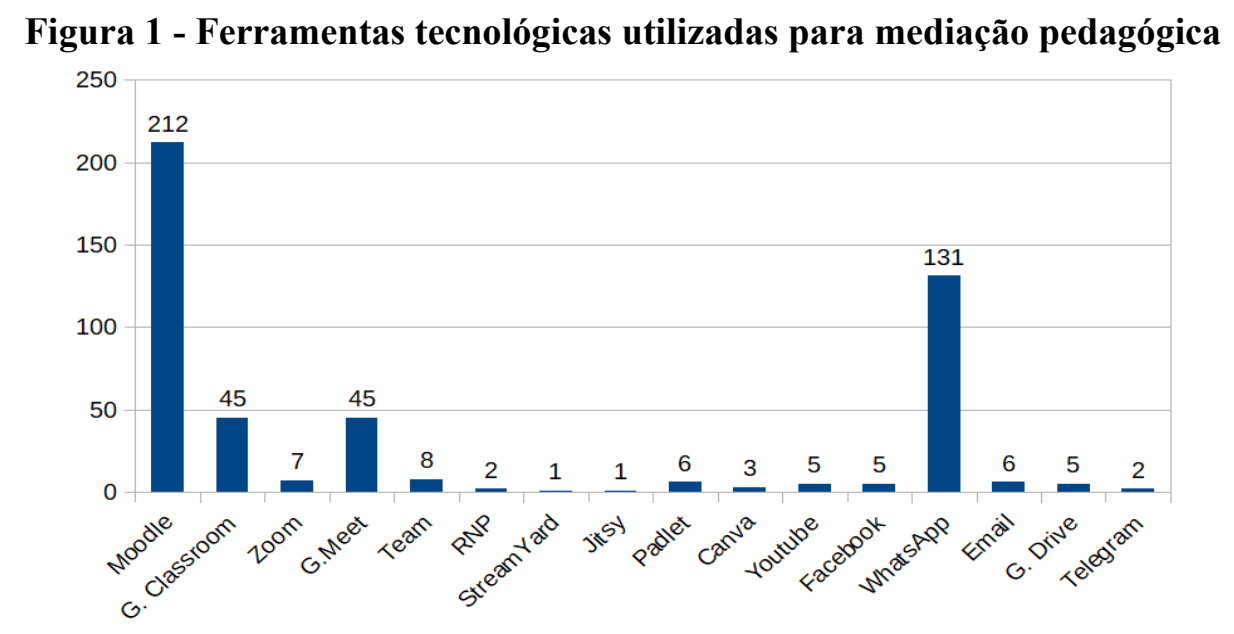

Fonte: os autores

Como pode ser visto na Figura 1, o Moodle foi o ambiente virtual de ensino e aprendizagem mais citado (91,8\%), sendo seguido do Google Classroom (19,5\%) e, com menor expressividade o Teams e o RNP. A escolha do ambiente, segundo os professores, se dá, principalmente, por ser o ambiente virtual institucional. Neste contexto, podemos inferir que a escolha do Moodle pelas instituições de ensino pode V. $19 \mathrm{~N}^{\mathrm{o}} 1$, julho, 2021 RENOTE 
estar relacionado ao fato do mesmo ser um software livre, modular e personalizado, que permite que cada instituição provenha configurações de forma a atender suas necessidades. Este resultado relacionado a preferência pelo Moodle está em consonância com o que afirmam Gomes e Pimentel (2021).

Observa-se ainda, que as ferramentas de webinar como o Google Meet, Stream Yard, Zoom, e Jitsy, vêm sendo usadas pelos professores para mediação pedagógica, normalmente junto ao uso dos AVEA. Estas ferramentas têm como vantagem propiciar o contato com os estudantes de forma síncrona, aproximando-se da presencialidade. No entanto, a mesma tem como desvantagem a necessidade de uma banda de internet com qualidade, o que nem sempre propicia a acessibilidade de todos os estudantes.

Os professores citam ainda o uso do Youtube como ferramenta para disponibilização de conteúdos. O Youtube é uma plataforma de distribuição de vídeos, acessada tanto nacional como mundialmente. Segundo Junges e Gatti (2019) o Youtube vai além do compartilhamento de materiais audiovisuais, mas propicia a interação entre usuários, a troca de informações, além de flexibilizar a aprendizagem. Embora essa ferramenta já fosse utilizada antes da pandemia, como apresentado no trabalho de Junges e Gatti (2019), a mesma vem possibilitando o compartilhamento de conteúdos neste período pandêmico. Uma das vantagens do Youtube é a compatibilidade tanto no ambiente virtual Moodle como Classroom, sendo um recurso educacional interessante.

Outros ambientes de compartilhamento de informações citados pelos respondentes são as redes sociais Facebook, Whatsapp, Telegram. Apesar destas não serem consideradas um ambiente de ensino e aprendizagem, vêm sendo amplamente exploradas neste momento pandêmico, principalmente o Whatsapp. De acordo com os professores, seu uso está associado ao contato rápido e direto com os estudantes para sanar dúvidas e distribuir pequenos conteúdos como podcasts ou áudio narrativas. Esse dado é concordante com o que afirmam Da Silva e Rocha (2020), que analisaram o uso desta rede social na educação. Segundo os autores o uso do Whatsapp se caracteriza por uma linguagem dinâmica e podem contribuir para práticas pedagógicas mais flexíveis e personalizadas, embora requeira que os sujeitos possuam smartphone, acesso à internet e instantaneidade da comunicação.

Quanto ao Facebook, Soares et. al (2018) afirmam que esta rede social "aproxima os agentes do processo de aprendizagem à medida que provê maior liberdade de expressão, o que resulta em maior participação dos estudantes e consequentemente na construção do conhecimento na coletividade". No entanto, o Facebook não permite a organização do conteúdo de forma planejada, e requer um monitoramento dos estudantes, para que as postagens sejam pertinentes aos conteúdos e feedback rápido.

Os professores apontam ainda usar o correio eletrônico (email) para distribuição de conteúdos e a ferramenta do Google Drive, que são formas mais tradicionais de compartilhamento de conteúdo. Estas ferramentas podem ser úteis para o envio de materiais, no entanto não apresentam atratividade, nem possibilidade de acompanhamento dos estudantes. Ademais, as informações compartilhadas nesses ambientes podem, se em grande número, tornarem-se desordenadas.

Arguimos os professores se participaram de algum curso de formação para uso de AVEA, sendo que 51,0\% dos respondentes afirma ter participado de capacitação antes da pandemia e 31,4\% após a necessidade de distanciamento social e mediação pedagógica digital. Apenas 17,6\% não participou de cursos de formação ou capacitação para o uso pedagógico das TIC. Nesse sentido, podemos inferir que os professores possuíam certa fluência no uso dos AVEA, visto que participaram de cursos formativos. 
Quanto a forma de uso do AVEA nosso primeiro questionamento foi sobre como os professores o organizam. Esse dado pode dar uma ideia de como ocorre o planejamento didático da disciplina. A maioria dos professores organiza o ambiente por data, assim, os estudantes podem ter uma ideia detalhada de cada conteúdo abordado no dia-a-dia. Já a organização por unidades de estudo é adotada por 33,8\% dos professores, esta forma de organização possibilita a correlação de conceitos contidos em uma unidade de estudo e pode contribuir para que os estudantes façam estas conexões. Os demais professores organizam seu ambiente por assunto, assemelhando-se à organização por unidades de estudo e os demais respondentes afirmam que esta organização depende da disciplina que está sendo ministrada.

Esses dados nos trazem indícios de que os professores, de alguma forma, têm um cuidado com o planejamento didático-pedagógico de sua disciplina, encontrando diferentes possibilidades de organizar o conteúdo para atender às suas necessidades. No intuito de compreender como se dá o processo de mediação pedagógica, investigamos quais os recursos educacionais os professores têm disponibilizado nos AVEA.

Os dados retornantes podem ser vistos na Figura 2, onde observa-se que, grande parte dos professores, distribui conteúdos autorais aos seus estudantes. A produção de materiais autorais, envolve não apenas os saberes da docência como requerem uma transposição de saberes, de forma a transformar o saber disciplinar em um saber a ser ensinado. Esse processo modifica a performance docente, pois conduz o professor a uma reflexão sobre o contexto dos estudantes, o conteúdo a ser abordado e qual a forma de fazê-lo para que atenda aos objetivos educacionais almejados.

Figura 2 - Frequência dos tipos de recursos educacionais disponibilizados para os estudantes

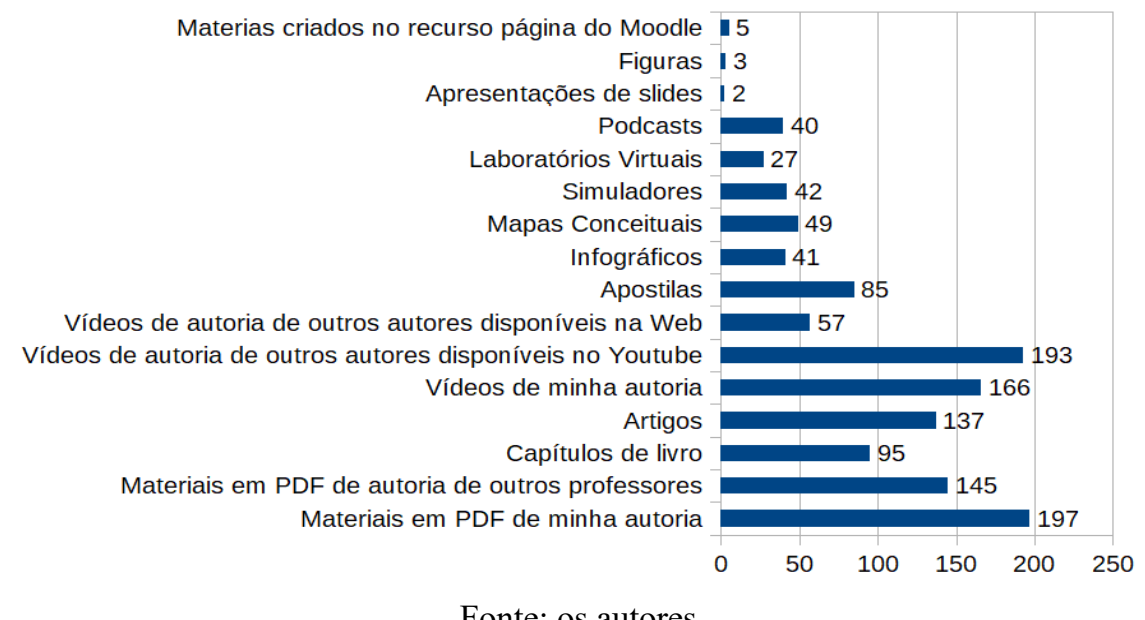

Fonte: os autores

Por outro lado, observamos ainda que grande parte dos professores distribui conteúdos de forma mais tradicional, como capítulos de livro, artigos, além de realizarem curadoria de materiais já disponibilizados na rede como os materiais em PDF de outros autores e vídeos de autoria de outros autores. Chama a atenção que a disponibilização de materiais multimídia, no formato de vídeo vem sendo bastante explorada pelos professores e, como afirmam Junges e Gatti (2019), os vídeos podem contribuir para flexibilizar a aprendizagem. Outro dado interessante, é que os professores usam uma diversidade de recursos educacionais para mediação pedagógica, o que pode contribuir para flexibilização da aprendizagem, e para despertar o interesse dos estudantes, como uso de recursos mais interativos. 
Questionamos sobre como eram as atividades de estudo disponibilizadas aos estudantes, no período pandêmico. Os dados retornantes podem ser vistos na Figura 3.

Figura 3 - Atividades de estudo e atividades avaliativas disponibilizadas para os estudantes

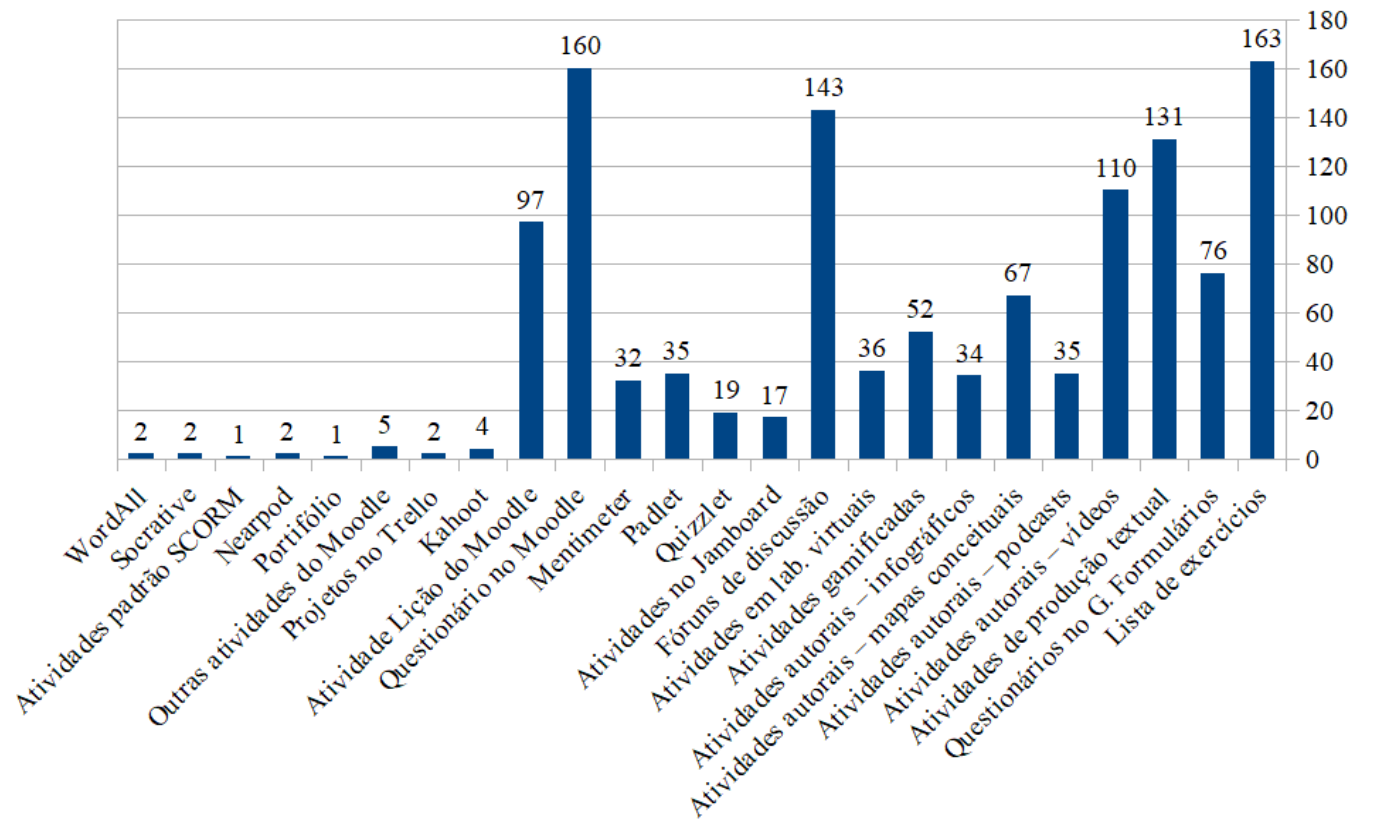

Fonte: os autores

Como pode-se observar na Figura 3, as atividades com maior frequência de citação foram as listas de exercícios, seguida do Questionário no Moodle. Estes dados eram esperados, visto que este tipo de atividade são as mais habituais no ensino presencial e também atividades muito comuns em cursos da área de exatas, por outro lado, os fóruns de discussão surgem dentre as atividades com alta frequência de citação e são comumente atividades comuns nos debates e discussões do ensino presencial, principalmente na área das ciências sociais e humanas. Assim, consideramos que estes dados surgem em decorrência dos professores buscarem no ensino remoto, alternativas para reproduzir suas práticas do ensino presencial.

Por outro lado, vislumbramos na Figura 3 elementos de inovação da práxis docente, tendo os professores como mediadores do processo de aprendizagem, desafiando estudantes a se tornarem copartícipes por meio das atividades autorais. Além disso, embora em menor frequência, observamos que os professores têm buscado propor atividades de estudo mais interativas para engajar os estudantes no processo.

\section{Vantagens e desvantagens da Mediação Pedagógica Online}

Os dados retornantes do formulário nos permitiram categorizar as principais vantagens e desvantagens apontadas pelos respondentes, quanto a mediação pedagógica online. As categorias foram elencadas a posteriori, sendo que a frequência, ou seja, o número de vezes em que aparecem na amostra total, foi um dos fatores condicionantes da criação da categoria. As categorias que tiveram frequências inferiores a 7 foram descartadas. Os dados categorizados são apresentados no Quadro 1. 
Quadro 1 - Frequência das categorias de análise.

Qual o maior desafio que você encontra ao produzir seus materiais no AVEA?

\begin{tabular}{|l|c|}
\hline \multicolumn{1}{|c|}{ Categoria } & Frequência \\
\hline Gestão do Tempo & 76 \\
\hline Conhecimento e expertise para o uso da plataforma & 42 \\
\hline Transposição/Adequação da linguagem & 21 \\
\hline Material confiável e adequado a realidade dos estudantes e professor & 21 \\
\hline Gravação de vídeo-aulas & 18 \\
\hline Ambiente e equipamentos adequados & 17 \\
\hline Acesso e interação dos estudantes no AVEA & 17 \\
\hline Criatividade na elaboração de recursos e atividades & 15 \\
\hline Nenhum & 9 \\
\hline & \\
\hline Adequação dos estudos conforme a disponibilidade dos alunos & 50 \\
\hline Organização de conteúdos & 24 \\
\hline Diversidade de avaliações/materiais de estudo dentro da mesma turma & 21 \\
\hline Maior interação dos alunos e professores & 16 \\
\hline Possibilidade de rever aulas gravadas várias vezes e ter o conteúdo disponível a & 14 \\
\hline qualquer momento & 13 \\
\hline Facilidade de acesso & 13 \\
\hline Monitoramento do acesso dos estudantes & 12 \\
\hline Autonomia e engajamento dos alunos & 12 \\
\hline Uso deve ser de forma complementar (híbrido) & 10 \\
\hline Fácil armazenamento de materiais & 7 \\
\hline Maior flexibilização & 7 \\
\hline Nenhuma vantagem & \\
\hline For & \\
\hline
\end{tabular}

Fonte: os autores

Conforme pode-se observar no Quadro 1, o maior desafio encontrado pelos professores refere-se à gestão do tempo. Isso já era esperado, visto que com a necessidade de mediação online a demanda por produção de material didático digital cresceu. Além disso, gerir o tempo em consonância com as atividades ocupacionais da casa e da família, podem contribuir para essa elevada frequência.

Por outro lado, a gestão do tempo está correlacionada a outros desafios que foram citados, como a expertise nos ambientes virtuais, a produção de vídeo-aulas, o tempo requerido para transposição e adaptação da linguagem ao nível de compreensão dos estudantes, ou ainda com o tempo para curadoria de materiais de autoria de outros profissionais, assim como a disponibilidade de ambientes e equipamentos adequados, além da criatividade. Santos, Klein e Barin (2018), afirmam que "a produção de material didático é comumente um desafio ao fazer docente, pois requer a fluência pedagógica para que ocorra a transposição didática, transformando os saberes - saber sábio ao saber a ser ensinado", ou seja, estes autores corroboram a ideia de que a fluência tecnológico-pedagógica é um desafio a ser transposto no processo de produção de recursos educacionais.

Se por um lado a adequação de materiais demanda tempo, por outro ela surge como a categoria mais citada enquanto vantagem do uso dos AVEA. Isto demonstra o quanto os professores têm procurado alternativas para mediação pedagógica durante a V. $19 \mathrm{~N}^{\mathrm{o}} 1$, julho, 2021 
pandemia. Outras categorias que se destacaram positivamente foram a possibilidade de organização dos materiais no AVEA e a diversidade de materiais e formas de avaliação. Esta última, pode ter contribuído para que os professores apontassem maior interação, embora a mesma tenha surgido também como desvantagem.

Estes dados sugerem que a participação e engajamento dos estudantes depende do tipo de atividade proposta. É provável que os professores que propuseram atividades de estudo ou atividades avaliativas autorais, como a produção de vídeos, infográficos e podcasts, tenham tido certa resistência inicial, mas maior engajamento dos estudantes, tornando-os sujeitos ativos do processo. Por outro lado, salientamos que o uso de materiais didáticos de baixa interatividade, assim como o alto volume de materiais disponibilizados, podem contribuir para a menor interação dos estudantes no ambiente.

Outra categoria elencada como vantagem foi a possibilidade de visualização das aulas gravadas e os conteúdos a qualquer momento. Essa vantagem pode ser abordada sob a ótica da flexibilidade, visto que os estudantes com maior dificuldade podem estabelecer o seu ritmo de aprendizagem, além de possibilitar a flexibilidade temporal.

Observa-se ainda no Quadro 1, que 9 dos 239 respondentes não encontraram dificuldades para mediar a aprendizagem nos AVEA, enquanto que 7 deles também não vislumbram nenhuma vantagem. Os professores que não encontraram dificuldades, certamente possuem maior fluência para o uso pedagógico das TIC. Por outro lado, o número de professores que não vislumbra vantagens no uso dos ambientes virtuais é exatamente igual ao número de professores que afirma que não pretende fazer uso dos mesmos após o período pandêmico.

Investigando melhor as respostas dos professores que não pretendem utilizar o ambiente, verificamos que 4 destes não participaram de nenhum curso de formação e seus materiais são bastante tradicionais, muito similares àqueles utilizados no ensino presencial. Os demais justificam que seus cursos têm características específicas que requerem o desenvolvimento de habilidades e, que nestes casos, apenas os AVEA não propiciam o desenvolvimento das mesmas.

Por fim, arqguimos os professores sobre a continuidade do uso do AVEA após o período pandêmico. Com base nos dados retornantes, embora alguns encontrem dificuldade em prover a mediação nos ambientes virtuais, apenas 7 professores não pretendem seguir utilizando. Assim, podemos inferir que a pandemia contribuiu para romper paradigmas sobre a convergência das modalidades de ensino, integrando à modalidade presencial, ferramentas das TIC para apoiar a mediação pedagógica.

\section{Considerações Finais}

O uso dos AVEA cresceu com a necessidade de mediação pedagógica online, decorrente da pandemia Covid-19, no intuito de compreender como estes estão sendo utilizados na EPT, vislumbramos desafios e potencialidades. Os maiores desafios encontrados pelos professores estão a demanda de tempo, que em parte se relaciona à não fluência para o uso dos recursos das TIC, embora grande parte tenha tido formação para tal, além do aumento da demanda de trabalho (produção de materiais diversos sem equipamentos e ambientes adequados). São citadas ainda às questões de acesso a equipamentos e à rede mundial de computadores, principalmente pelos estudantes.

Para além dos desafios, os professores encontraram vantagens em usar os ambientes virtuais, dentre estas a possibilidade de adaptar e organizar os materiais nas plataformas, além de criar materiais e atividades diversas. Outra vantagem citada é possibilidade de monitorar os estudantes no processo de ensino e aprendizagem. Estas 
vantagens poderão influir na continuidade do uso dos AVEA após o período pandêmico.

Assim, podemos inferir que a pandemia trouxe consigo muitos desafios para mediação pedagógica, no entanto, proporcionou aos professores experimentarem novas formas de ensinar e aprender, permitindo tornarem-se autores de seu próprio material didático, o que certamente trará impacto positivo na performance docente. Além disso, propor atividades autorais para os estudantes também é um dos fatores que merece destaque, visto que instiga uma postura mais ativa no processo de aprendizagem, contribuindo no engajamento destes.

\section{Referências}

AL-MAROOF, Rana A. Saeed; AL-EMRAN, Mostafa. Students Acceptance of Google Classroom: An Exploratory Study using PLS-SEM Approach. International Journal of Emerging Technologies in Learning, v. 13, n. 6, 2018.

BARDIN, Laurence. Análise de Conteúdo. 1ªed. Editora Almedina. 2011.

BARIN, Cláudia Smaniotto; BASTOS, Giséli Duarte; MARSHALL, Débora. A elaboração de material didático em ambientes virtuais de ensino-aprendizagem: o desafio da transposição didática. RENOTE-Revista Novas Tecnologias na Educação, v. 11, n. 1, 2013.

DOS SANTOS, Cassiano Vasconcelos; KLEIN, Vanessa; BARIN, Claudia Smaniotto. Produção de material didático digital para o ensino de química: desafios e possibilidades. Redin-Revista Educacional Interdisciplinar, v. 7, n. 1, 2018.

COSTA, Ana Paula et al. Interação, cooperação e sistematização da aprendizagem em ambiente virtual: uma proposta metodológica inovadora. RENOTE-Revista Novas Tecnologias na Educação, v. 10, n. 1, 2012.

DA SILVA, João Batista. Ensino híbrido e Tecnologias digitais na educação básica: algumas contribuições do Google classroom. Revista Cocar, v. 14, n. 30, 2020.

DA SILVA, Ivanderson Pereira; DE BURGOS ROCHA, Fernanda. Implicações do uso do whatszapp na educação. Revista EDaPECI, v. 17, n. 2, p. 161-174, 2017.

DE BRITO, Lélis Maia et al. Ambientes virtuais de aprendizagem como ferramentas de apoio em cursos presenciais e a distância. RENOTE-Revista Novas Tecnologias na Educação, v. 11, n. 1, 2013.

GOMES, Alex Sandro; PIMENTEL, Edson Pinheiro. Ambientes Virtuais de Aprendizagem para uma Educação mediada por tecnologias digitais. In: PIMENTEL, Mariano; SAMPAIO, Fábio F.; SANTOS, Edméa (Org.) . Informática na Educação: ambientes de aprendizagem, objetos de aprendizagem e empreendedorismo. Porto Alegre: Sociedade Brasileira de Computação, 2021. (Série Informática na Educação CEIE-SBC, v.5) Disponível em: $<$ https://ieducacao.ceie-br.org/ava $>$

JUNGES, Débora de Lima Velho; GATTI, Amanda. Estudando por vídeos: o Youtube como ferramenta de aprendizagem. Informática na Educação: teoria \& prática, Porto Alegre, v. 22, n. 2, p. 143-158, maio/ago. 2019.

MOREIRA, Maria Eduarda Souza et al. Metodologias e tecnologias para educação em tempos de pandemia COVID-19. Brazilian Journal of Health Review, v. 3, n. 3, p. 6281-6290, 2020.

RUY, Rosimari.; BELDA, Francisco Rolfsen. Classroom versus Moodle: Um relato descritivocomparativo a partir da experiência da construção de um curso on-line. Ciências em Foco, Campinas, SP, v. 14, p. e021002, 2021. 
SANTOS JR, Verissimo Barros dos; MONTEIRO, Jean Carlos da Silva. Educação e covid-19: as tecnologias digitais mediando a aprendizagem em tempos de pandemia. Revista EncantarEducação, Cultura e Sociedade, v. 2, p. 01-15, 2020.

SOARES, Aline Bairros et al. Construindo saberes nas redes sociais. RENOTE-Revista Novas Tecnologias na Educação v. 16, n. 1, 2018.

TARDIF, Maurice. Saberes Docentes e Formação Profissional. 8a edição Petrópolis, RJ: Vozes, 2007.

ZIBETTI, Marli Lúcia Tonatto; PEREIRA, Sidnéia Ribeiro. Mulheres e professoras: repercussões da dupla jornada nas condições de vida e no trabalho docente. Educar em revista, n. spe2, p. 259-276, 2010. 